\title{
Management of broncholithiasis
}

\author{
Sheila Krishnan ${ }^{1}$, Christopher M. Kniese ${ }^{1}$, Mark Mankins ${ }^{2}$, Darel E. Heitkamp ${ }^{3}$, Francis D. Sheski ${ }^{1}$, \\ Kenneth A. Kesler ${ }^{2}$
}

${ }^{1}$ Division of Pulmonary, Critical Care, Sleep, and Occupational Medicine, ${ }^{2}$ Division of Cardiothoracic Surgery, ${ }^{3}$ Department of Radiology and Imaging Sciences, Indiana University School of Medicine, Indianapolis, IN 46202, USA

Contributions: (I) Conception and design: All authors; (II) Administrative support: None; (III) Provision of study materials or patients: FD Sheski, DE Heitkamp, KA Kesler; (IV) Collection and assembly of data: S Krishnan, CM Kniese; (V) Data analysis and interpretation: None; (VI) Manuscript writing: All authors; (VII) Final approval of manuscript: All authors.

Correspondence to: Sheila Krishnan, DO. Lung Transplant and Pulmonary Hypertension Fellow, Division of Pulmonary, Critical Care, Sleep, and Occupational Medicine, Indiana University School of Medicine, Gatch Hall, CL 260, 1120 West Michigan Street, Indianapolis, IN 46202, USA. Email: krishnan.sheila@gmail.com.

\begin{abstract}
Broncholithiasis is a condition in which calcified material has entered the tracheobronchial tree, at times causing airway obstruction and inflammation. Broncholiths generally originate as calcified material in mediastinal lymph nodes that subsequently erode into adjacent airways, often as a result of prior granulomatous infection. Disease manifestations range from asymptomatic stones in the airway to lifethreatening complications, including massive hemoptysis and post-obstructive pneumonia. Radiographic imaging, particularly computed tomography scanning of the chest, is integral in the evaluation of suspected broncholithiasis and can be helpful to assess involvement of adjacent structures, including vasculature, prior to any planned intervention. Management strategies largely depend on the severity of disease. Observation is warranted in asymptomatic cases, while therapeutic bronchoscopy and surgical interventions may be necessary for cases involving complications. Bronchoscopic extraction is often feasible in cases in which the broncholith is freely mobile within the airway, whereas partially-embedded broncholiths represent additional challenges. Surgical intervention is indicated for advanced cases deemed not amenable to endoscopic management. Complex cases involving complications such as massive hemoptysis and/or bronchomediastinal fistula formation are best managed with a multidisciplinary approach, utilizing expertise from fields such as pulmonology, radiology, and thoracic surgery.
\end{abstract}

Keywords: Surgical management; bronchoscopy; broncholithiasis

Submitted Feb 23, 2018. Accepted for publication Jun 20, 2018.

doi: $10.21037 /$ jtd.2018.07.15

View this article at: http://dx.doi.org/10.21037/jtd.2018.07.15

\section{Overview}

Broncholithiasis refers to the presence of calcified material that erodes into the lumen of the tracheobronchial tree or lung parenchyma, potentially causing inflammation and obstruction (1). Consequences from broncholithiasis range widely from being asymptomatic to life threatening such as recurrent pneumonias, hemoptysis, and bronchoesophageal fistula. Management varies depending upon several factors including patient symptoms, associated lung disease, and mobility of the broncholith within the airway, but typically involves either observation or intervention via bronchoscopy or thoracic surgery. This paper reviews the etiology, clinical presentation, radiologic appearance, and management of broncholithiasis.

\section{Definition and etiology}

The term broncholithiasis is the condition that arises when a broncholith causes airway irritation, obstruction, or erosion into adjacent structures (2). The vast majority of broncholiths are formed by the partial or complete erosion 
Table 1 Summary of publications of clinical presentations and radiographic findings in broncholithiasis

\begin{tabular}{|c|c|c|c|c|}
\hline Publication & Patients & Etiology & Clinical presentation & Radiographic findings \\
\hline $\begin{array}{l}\text { Kim } \\
2005(11)\end{array}$ & 9 & $\begin{array}{l}\text { Fungal infection } \\
\text { (actinomycosis) }\end{array}$ & $\begin{array}{l}\text { Cough }(n=8,89 \%) \text {, sputum production } \\
(n=8,89 \%) \text {, hemoptysis }(n=5,55 \%)\end{array}$ & $\begin{array}{l}\text { Distal obstruction }(n=8,89 \%) \text { atelectasis }(n=2,22 \%) \text {, } \\
\text { central necrosis within consolidation }(n=4,44 \%) \text {, } \\
\text { cavitary lesion ( } n=3,33 \%) \text {, airway narrowing }(n=2 \text {, } \\
22 \%) \text {, airway obstruction }(n=7,78 \%) \text {, bronchiectasis } \\
(n=4,44 \%) \text {, pleural thickening }(n=2,22 \%)\end{array}$ \\
\hline
\end{tabular}

of an adjacent calcified peribronchial lymph node into the airway lumen. Erosion of a broncholith into the airway is thought to result from the repeated physical contact of a calcified lymph node with an adjacent bronchus during normal respiratory motion (1). Nodal calcification in the thorax most often occurs from long-standing lymphadenitis related to fungal or mycobacterial infections, with Histoplasma capsulatum representing the most common causative organism in the United States. Less common infectious etiologies include tuberculosis, actinomycosis, coccidioidomycosis, and cryptococcosis (3). Due to airway anatomy and normal lymph node distribution, the most commonly affected bronchi are the proximal right middle lobe bronchus, the bronchus intermedius, and the origin of the anterior segment right upper lobe bronchus, in order of frequency $(1,3-5)$.

Other etiologies of broncholithiasis are less common. Broncholiths can arise as extrinsic calculi from aspirated foreign material (4), such as aspirated fragments of bone or foreign debris which calcifies in situ within the airway over time. Calcified cartilage rings in the airway wall can also extrude and become sequestered inside the lumen of the bronchus forming broncholiths. Calcified material from remote locations within the thorax, such as fragments of calcified pleural plaques, can migrate over time and eventually erode into a bronchus (6). Extremely rare cases of calcified endobronchial hamartomas and carcinoid tumors, primary ciliary dyskinesia-associated broncholiths, and silicosis-associated egg shell lymph node broncholiths have also been reported (6-8).

\section{Clinical presentation, symptoms, and radiographic findings}

The severity and type of patients' symptoms are typically related to the degree of bronchial inflammation, obstruction, or involvement of adjacent structures (Tables 1-3). Given that the most common symptom is chronic cough, most patients present in the outpatient setting (3). Cough associated with broncholithiasis can be dry or productive of mucous, purulence, or "gravel". The latter symptom, termed lithoptysis, occurs when fragments of the broncholith are expectorated. Symptoms or conditions that may necessitate inpatient care include pneumonia, hemoptysis, and the development of fistulae between the bronchi and mediastinal structures (1).

While routine chest radiographs can reveal findings of hilar calcifications or parenchymal infiltrates (3), they lack the resolution to identify the causative broncholith (Figure 1A). On occasion, a broncholith cannot be identified even on diagnostic bronchoscopy due to partial erosion of the node into the airway, with a reported incidence 
Table 2 Major series of bronchoscopic management of broncholithiasis

\begin{tabular}{|c|c|c|c|c|c|}
\hline Publication & Patients & Procedures & $\begin{array}{l}\text { Type of } \\
\text { bronchoscopy }\end{array}$ & Outcomes & Complications \\
\hline Cerfolio 2008 (1) & 50 & 38 & Rigid & 29 attempted, 29 removed (100\%) & None reported \\
\hline Menivale 2005 (13) & 4 & 4 & Flexible & 2 attempted, 2 removed (100\%) & None reported \\
\hline Yi 2005 (14) & 2 & 2 & Flexible & 2 attempted, 2 removed & None reported \\
\hline Cole 1986 (16) & 42 & 40 & $\begin{array}{l}\text { Flexible and } \\
\text { Rigid }\end{array}$ & $\begin{array}{l}8(19 \%) \text { removed; attempts not } \\
\text { reported; } 75 \% \text { with rigid }\end{array}$ & None reported \\
\hline Dixon $1984(3)$ & 19 & 18 & $\begin{array}{l}\text { Flexible and } \\
\text { Rigid }\end{array}$ & $\begin{array}{l}8 \text { attempted, } 4 \text { removed (50\%); (75\%) } \\
\text { with rigid }\end{array}$ & None reported \\
\hline Moersch 1959 (18) & 87 & 33 & Unavailable & 33 attempted; success rate unknown & Unavailable \\
\hline
\end{tabular}

Table 3 Major series of surgical management of broncholithiasis

\begin{tabular}{|c|c|c|c|c|}
\hline Publication & Patients & Etiology & Type of surgery & Complications \\
\hline $\begin{array}{l}\text { Cerfolio } \\
2008(1)\end{array}$ & 5 & $\begin{array}{l}\text { BE fistula }(n=2,40 \%) \text {; fixed } \\
\text { broncholith }(n=3,60 \%)\end{array}$ & $\begin{array}{l}\text { Thoracotomy with } L N \text { curettage and/or } \\
\text { removal }(n=5,100 \%)\end{array}$ & None reported \\
\hline $\begin{array}{l}\text { Cole } \\
1986(16)\end{array}$ & 25 & $\begin{array}{l}\text { Fixed broncholiths, } \\
\text { symptoms after } \\
\text { bronchoscopy, hemoptysis } \\
\text { from histoplasmosis, } \\
\text { aspergillosis, and } \\
\text { tuberculosis }\end{array}$ & $\begin{array}{l}\text { Thoracotomy }(n=26,100 \%) \text {; segmental } \\
\text { resection }(n=11,42 \%) \text {, lobectomy } \\
(n=11,42 \%) \text {, bronchotomy with } \\
\text { broncholithectomy }(n=3,12 \%) \text {, } \\
\text { tracheoesophageal fistula repair }(n=1 \text {, } \\
4 \%)\end{array}$ & None reported \\
\hline
\end{tabular}

$\mathrm{BE}$, bronchoesophageal; LN, lymph node; PA, pulmonary artery.

ranging from $28-56 \%$ of cases $(3,12,17,21)$. Computed tomography (CT) therefore plays a crucial role in the initial diagnosis, accurately identifying the specific location of the broncholith, the degree of endobronchial obstruction, and the presence of associated findings such as atelectasis, consolidation, bronchiectasis, air trapping, mucoid impaction 

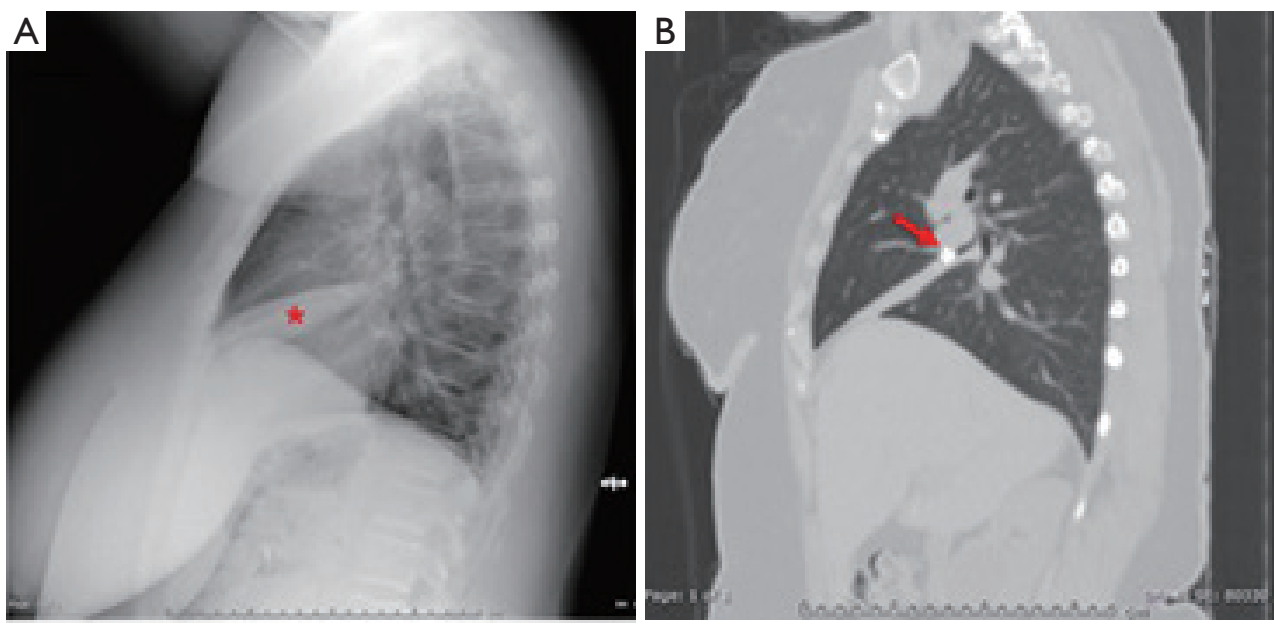

Figure 1 Comparison of plain radiograph to computed tomography (CT) scan in the same patient with broncholithiasis. (A) Lateral chest radiograph demonstrates right middle lobe atelectasis (asterisk); (B) CT scan in sagittal reformat reveals the causative broncholith (arrow) obstructing the proximal right middle lobe bronchus.
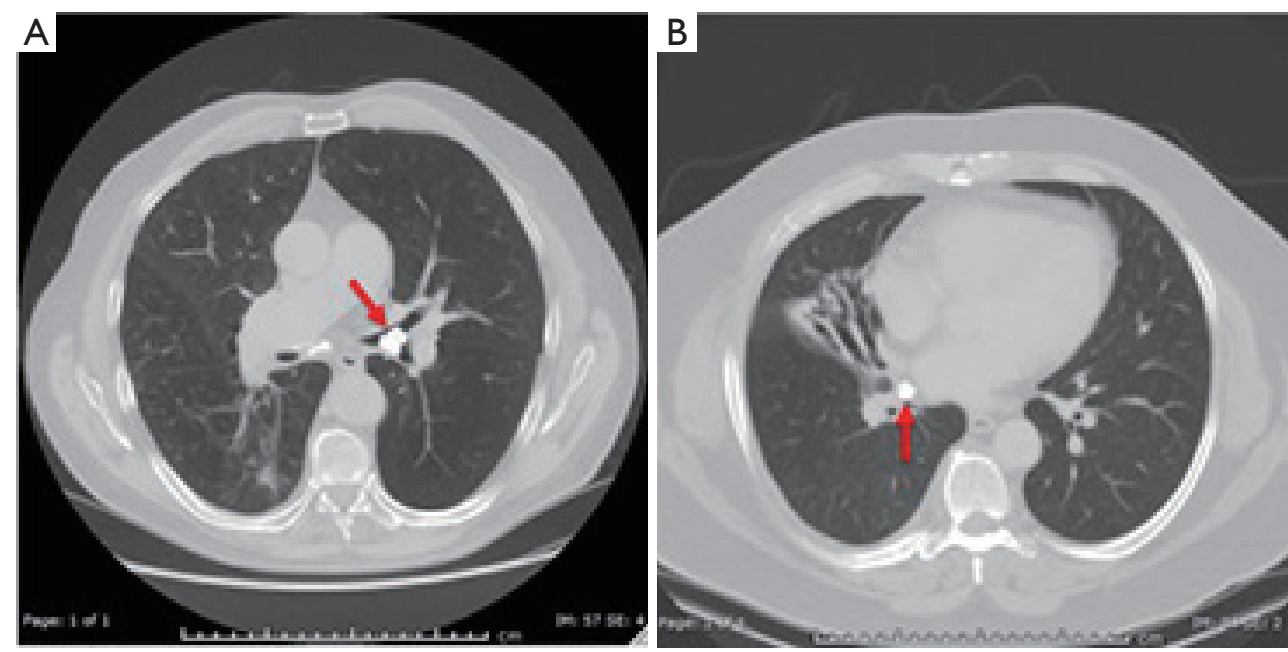

Figure 2 Common CT imaging findings in patients with broncholithiasis. (A) Axial chest CT image demonstrates a broncholith (arrow) in the left mainstem bronchus without parenchymal involvement; (B) axial chest CT image of a different patient demonstrates a broncholith (arrow) at the origin of the right middle lobe bronchus with associated bronchiectasis and parenchymal atrophy.

of a bronchus, or frank lung destruction (Figure $1 B$ and Figure 2) CT imaging may also show other sequelae of long standing lymphadenitis or granulomatous disease, including mediastinal calcifications, nodules, and scarring.

\section{Management}

\section{Conservative}

Management of broncholithiasis depends on several factors including patient symptoms, the size of the broncholith, its relationship with the airway wall, and its proximity to or involvement of adjacent thoracic structures. Indications for bronchoscopic or surgical intervention include symptoms related to intractable cough, recurrent pulmonary infections, symptomatic bronchiectasis, hemoptysis, and fistula formation. In general, conservative management in the form of observation is warranted in asymptomatic patients and those with minimal or non-recurring, non-life-threatening 

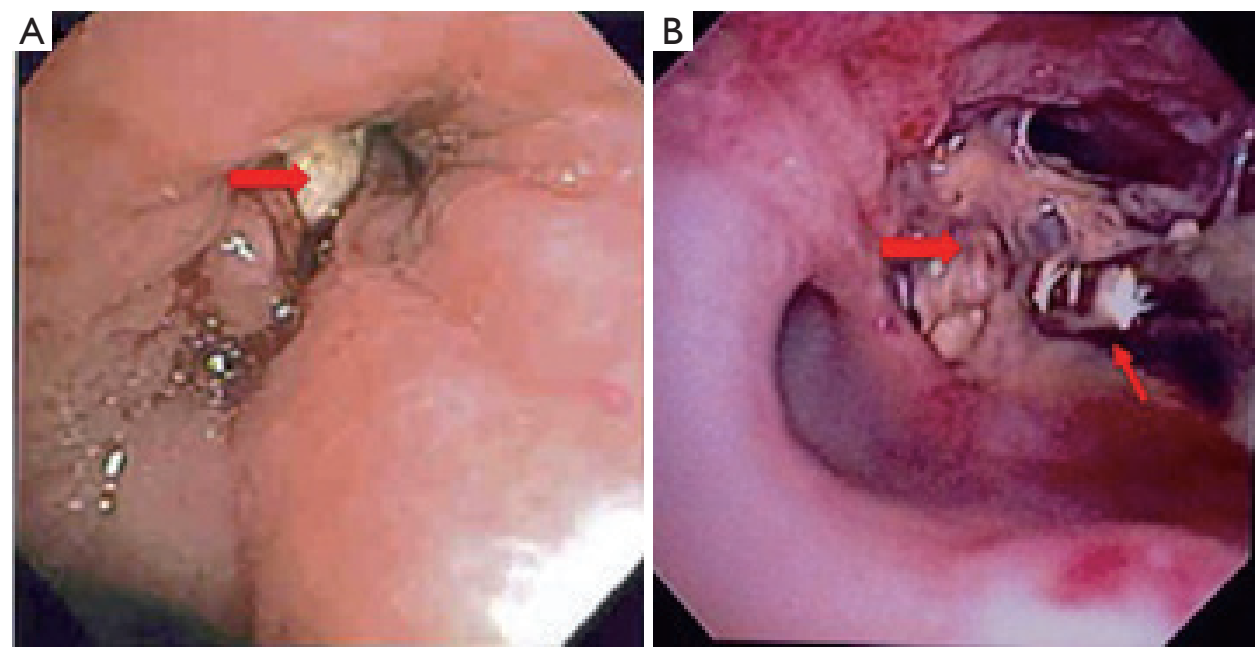

Figure 3 Bronchoscopic visualization of broncholiths. (A) Bronchoscopic visualization of broncholith in right mainstem bronchus (thick red arrow) with associated mucosal edema; (B) forceps extraction (thin red arrow) of broncholith (thick red arrow) during bronchoscopic intervention.

symptoms. Also, patients with significant comorbidities or limited life span who may not tolerate invasive therapy are candidates for conservative therapy. Conservative measures to consider include cough suppression, bronchodilators, and empiric antimicrobial therapy. If sputum gram stain and culture or other laboratory testing identifies a specific infection, then antimicrobial therapy can be tailored accordingly.

\section{Bronchoscopy}

Bronchoscopy has been described for both diagnostic and potentially therapeutic purposes in the symptomatic patient (22). When broncholithiasis is suspected based on clinical and radiographic findings, flexible bronchoscopy is often employed to confirm the diagnosis by direct visualization of a calcified stone in the airway $(3,15)$. The typical broncholith appears as a yellow or white concretion, sometimes with areas of dark discoloration (Figure $3 A$ ). When tapped with forceps through the working channel of the bronchoscope, it has a hard texture and may be either mobile or fixed. The adjacent airway mucosa is often inflamed and friable with blood oozing when touched. Granulation tissue may also be present. When the broncholith cannot be identified, evidence of airway distortion or inflammatory obstruction is typically observed.

In addition to confirming the diagnosis, bronchoscopy can aspirate secretions for therapeutic purposes and obtain cultures which may guide antibiotic therapy. During bronchoscopy, the degree of broncholith mobility should be assessed, as this may dictate further management. It is, however, occasionally difficult to assess the degree of mobility as well as any involvement of important structures beyond the bronchial wall, such as pulmonary vasculature. This underscores the need for CT imaging with intravenous contrast prior to any attempt at bronchoscopic removal with attention directed at identifying major vascular structures in the vicinity of the broncholith. Saline irrigation and forceps manipulation during bronchoscopy have been described as methods to assess the degree of attachment $(13,16)$ (Figure 3B). Use of topical lidocaine and epinephrine have been described to minimize bronchial wall bleeding during broncholith manipulation (23).

The pathophysiology of broncholithiasis represents a distinct entity when compared to other forms of foreign bodies in the airways (19). As such, bronchoscopic management may differ from traditional forms of foreign body removal where extraction using flexible or rigid bronchoscopy is often feasible (17). Historically, bronchoscopic broncholithectomy was not recommended due to concern of complications including bleeding, displacement of the broncholith causing obstruction, or iatrogenic creation of a fistula. The role of therapeutic bronchoscopy in the context of broncholithiasis has evolved however to include select cases (2). Olson et al. reported on 48 patients who underwent bronchoscopic removal with only a $4 \%$ complication rate (15). The authors determined that mobile broncholiths could be safely removed, as well 
as some partially-eroding broncholiths. In this series, there was a high risk of complications, particularly hemorrhage, when broncholiths were partially embedded in the bronchial wall (15). Cerfolio and colleagues reported their experience in 50 patients with broncholithiasis (1). The authors reached a similar conclusion that broncholiths which are mobile can be safely removed with bronchoscopy, whereas surgery is typically indicated for symptomatic patients not amenable to bronchoscopic treatment. In summary, retrospective studies support an initial attempt at bronchoscopic removal in cases where broncholiths are mobile or loosely attached to the bronchial wall.

During bronchoscopy, if forceps extraction is not readily feasible, more investigational options are available to facilitate removal. The use of a balloon catheter has been described for removal of a partially eroded broncholith (14). With this technique, the balloon is inserted distal to the stone. The balloon is then inflated and pulled back in an attempt to dislodge the stone proximally. This technique mimics that where a closed forcep is passed beyond the broncholith, opened, and then retracted. Stone fragmentation which facilitates extraction using holmiumyttrium aluminum garnet (Ho:YAG) (24) and neodymiumdoped yttrium aluminum garnet $(\mathrm{Nd}$ :YAG) $(15,25)$ lasers has been reported. Bronchoscopic lithotripsy similar to that used in nephrolithiasis has also been reported (26). More recently, the use of a cryotherapy probe for broncholithectomy was described. Some have advocated the use of rigid bronchoscopy with larger working channels (1) to facilitate stone extraction, however, this modality is generally now reserved for very select cases in which flexible bronchoscopy has failed (15). Use of a pediatric bronchoscope has been described to reach endobronchial lesions in the distal airways (27) Lastly, the use of a covered self-expandable metallic stent has been described in a case in which the broncholith was associated with a bronchoesophageal fistula (28). In a separate but similar case, endoscopic placement of an esophageal stent was described for a poor surgical candidate with bronchoesophageal fistula (29).

In the patient presenting with hemoptysis as a complication of broncholithiasis, diagnostic bronchoscopy should be pursued to identify the location of bleeding and etiology of hemoptysis, if possible. The decision to proceed with observation versus broncholith removal, however, should be based on the frequency and quantity of hemoptysis coupled with the predicted ease of broncholith removal. There are published reports of massive hemoptysis caused by broncholithiasis (30); however, management of bleeding due to bronchoscopic removal of broncholiths has scarcely been described. Techniques that have been described for other etiologies of hemoptysis may be useful in these cases. Placement in the lateral decubitus position, with the affected side down, has been proposed, as has the use of selective mainstem bronchus intubation (31). Likewise, insertion of a balloon catheter adjacent to the endotracheal tube to tamponade the site of bleeding has been described (31). These should be regarded as temporizing measures while definitive therapy is planned. Flexible or rigid bronchoscopy with various methods of cautery may be of some use. The use of endobronchial hemostatic devices placed via bronchoscopy has been described but has yet to achieve widespread adoption (32). Bronchial artery embolization or thoracic surgery is required for definitive therapy $(33,34)$.

In addition to hemorrhage, complications of bronchoscopic broncholithectomy include airway obstruction due to stone dislodgement, fistula creation, and damage to the bronchial wall $(15,35)$. On occasion, attempts at stone extraction can result in inadvertent advancement of the broncholith with distal airway occlusion, necessitating further intervention (23). Cases involving embedded broncholiths may lead to formation of bronchomediastinal or bronchoesophageal fistulae when the stone is removed $(28,36)$. Table 2 summarizes published series on bronchoscopic management of broncholithiasis. The highest reported success rates approach $100 \%$ for freely mobile broncholiths. The success rate of intervening on partially eroded or fixed broncholiths ranges from 0-48\% $(1,15)$. Bronchoscopic interventions for adherent broncholiths should only be attempted by experienced operators at specialized centers with appropriate interventional radiology and thoracic surgery expertise in case of serious complications. Moreover, in an otherwise healthy patient with significant distal lung destruction such as bronchiectasis or fistulization into an adjacent structure, high-risk bronchoscopic procedures should be avoided in deference of surgical intervention.

\section{Surgery}

Surgical intervention is indicated for symptomatic patients without precluding comorbidities in whom therapeutic bronchoscopy is unable to relieve the airway obstruction. These patients often suffer from complications related to recurrent pneumonia, hemoptysis, substantial distal bronchiectasis or parenchymal destruction, or fistulae between the airway and mediastinal structures (Figure 4) (13). While there is current enthusiasm to 

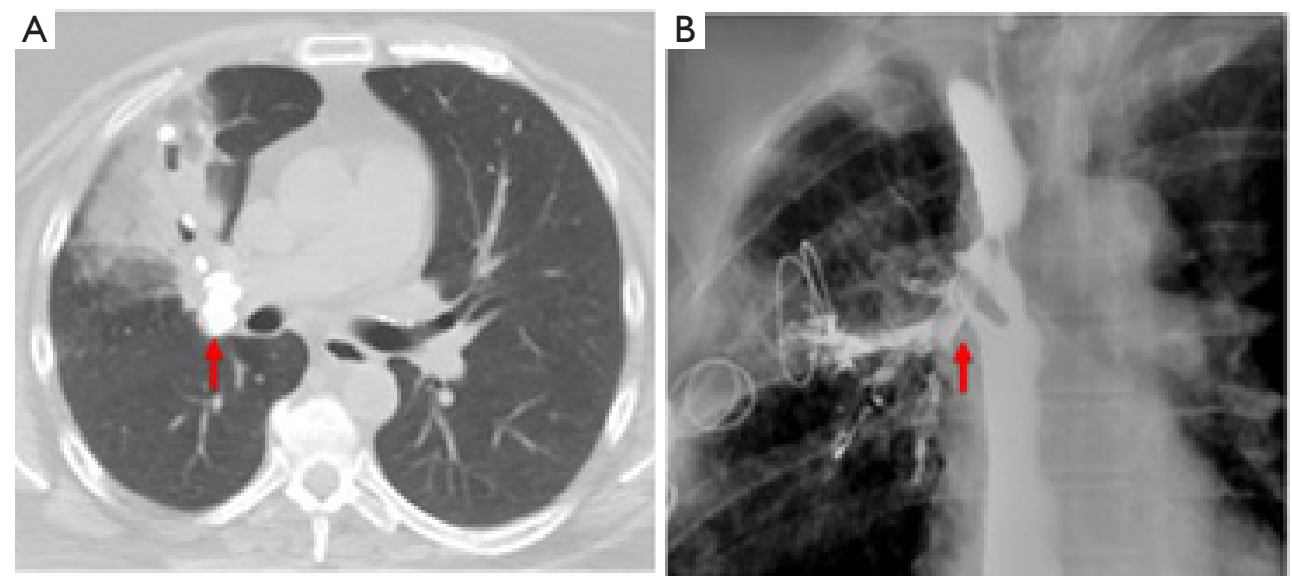

Figure 4 Advanced complications of broncholithiasis that required surgery. (A) Axial CT image of an otherwise healthy patient with several calcified lymph nodes surrounding the distal bronchus intermedius (arrow) with complete obstruction of the right middle lobe airway and secondary bronchiectasis and pneumonitis that was treated with thoracotomy and bilobectomy; (B) a separate case demonstrating a bronchoesophageal fistula (arrow) seen on gastrografin esophagram that developed after surgical removal of a broncholith in the bronchus intermedius. This case required a second thoracotomy with esophageal repair.

perform pulmonary surgery using minimally invasive approaches such as thoracoscopy or robotic technology, calcific fibrosis surrounding airway and pulmonary vasculature typically requires an open approach for the majority of these cases. Occasionally broncholiths can be removed through a small bronchotomy, followed by repair of the airway and takedown of any fistula if present, with interposition of pedicled soft tissue between the two structures, sparing normal pulmonary parenchyma (1).

An anatomic pulmonary resection is usually required for broncholiths causing hemoptysis or chronic obstruction with resultant end stage parenchymal damage (Figure $2 B$ and Figure 4) Inflammation and dense fibrosis are frequently encountered during lobar hilar dissection, which makes branch pulmonary artery isolation and division risky. In these cases, initial placement of an umbilical tape proximally around the main pulmonary artery prior to lobar hilar dissection will allow rapid control of inadvertent bleeding. In cases where the lobar bronchus and pulmonary branch vessels are densely adherent, occluding the main pulmonary artery then amputating the lobar hilum for initial lung removal, usually allows safe separation of the airway and vessels followed by independent closure. Finally, parenchymal sparing sleeve resections for patients with significant involvement of the right upper lobe hilum can be utilized to avoid pneumonectomy.

Table 3 summarizes the publications on surgical management of broncholithiasis. Potaris and colleagues reported their experience with 47 patients with broncholithiasis requiring surgical intervention (20). The majority of patients were found to have right-sided lesions. Pulmonary resection was required in $64 \%$ of patients, while $34 \%$ underwent broncholithectomy without pulmonary resection. We previously reported our experience in 49 patients who underwent surgery for complications of histoplasmosis, 13 of which had broncholithiasis (19) and were not candidates for bronchoscopic removal due to broncholith adherence. Indications for surgery included either recurrent pneumonia or hemoptysis. Twelve of these patients underwent lobectomy or bilobectomy. In Cerfolio's series, only 5 of 50 patients underwent surgery with thoracotomy and lymph node curettage, removal, or both (1). Potaris and colleagues documented the largest number of surgical cases and reports an intraoperative complication rate of $12.8 \%$ and a major postoperative complication rate of $15 \%$ (20). While the reported surgical morbidity appears high, to date there have been no operative deaths in published series. Given the potential for complications and the small but definite risk of recurrent broncholithiasis (20), surgery should be reserved for cases not amenable to conservative or bronchoscopic management.

\section{Conclusions}

The management of broncholithiasis can be challenging and should be individualized for symptomatic patients. A 
multidisciplinary approach with assessment by thoracic radiologists, interventional pulmonologists, and thoracic surgeons prior to implementing any treatment strategy is usually optimal for patient care. In cases of mobile or loosely attached broncholiths, therapeutic bronchoscopy is often effective with minimal risks. Bronchoscopic intervention in cases of partially eroded broncholiths does present risks of hemorrhage, broncholith dislodgement, and fistula formation, but can be considered by experienced operators at specialized centers capable of managing potential complications. In patients with acceptable operative risk levels, surgery remains the mainstay of treatment in cases with significant distal parenchymal destruction, severe hemoptysis, or where bronchoscopic intervention failed.

\section{Acknowledgements}

None.

\section{Footnote}

Conflicts of Interest: The authors have no conflicts of interest to declare.

\section{References}

1. Cerfolio RJ, Bryant AS, Maniscalco L. Rigid bronchoscopy and surgical resection for broncholithiasis and calcified mediastinal lymph nodes. J Thorac Cardiovasc Surg 2008;136:186-90.

2. Blanco Ramos M, Botana-Rial M, Garcia-Fontan E, et al. Update in the extraction of airway foreign bodies in adults. J Thorac Dis 2016;8:3452-6.

3. Dixon GF, Donnerberg RL, Schonfeld SA, et al. Advances in the diagnosis and treatment of broncholithiasis. Am Rev Respir Dis 1984;129:1028-30.

4. De S, De S. Broncholithiasis. Lung India 2008;25:152-4.

5. Kelley WA. Broncholithiasis: current concepts of an ancient disease. Postgrad Med 1979;66:81-6, 88, 90.

6. Seo JB, Song KS, Lee JS, et al. Broncholithiasis: review of the causes with radiologic-pathologic correlation. Radiographics 2002;22 Spec No:S199-213.

7. Carasso B, Couropmitree C, Heredia R. Egg-shell silicotic calcification causing bronchoesophageal fistula. Am Rev Respir Dis 1973;108:1384-7.

8. Kennedy MP, Noone PG, Carson J, et al. Calcium stone lithoptysis in primary ciliary dyskinesia. Respir Med 2007;101:76-83.
9. Tsubochi H, Endo S, Suhara K, et al. Endobronchial aspergillosis and actinomycosis associated with broncholithiasis. Eur J Cardiothorac Surg 2007;31:1144-6.

10. Ford MA, Mueller PS, Morgenthaler TI. Bronchoesophageal fistula due to broncholithiasis: a case series. Respir Med 2005;99:830-5.

11. Kim TS, Han J, Koh WJ, et al. Endobronchial actinomycosis associated with broncholithiasis: CT findings for nine patients. AJR Am J Roentgenol 2005; 185:347-53.

12. Conces DJ Jr, Tarver RD, Vix VA. Broncholithiasis: CT features in 15 patients. AJR Am J Roentgenol 1991;157:249-53.

13. Menivale F, Deslee G, Vallerand H, et al. Therapeutic management of broncholithiasis. Ann Thorac Surg 2005;79:1774-6.

14. Yi KY, Lee HK, Park SJ, et al. Two cases of broncholith removal under the guidance of flexible bronchoscopy. Korean J Intern Med 2005;20:90-1.

15. Olson EJ, Utz JP, Prakash UB. Therapeutic bronchoscopy in broncholithiasis. Am J Respir Crit Care Med 1999;160:766-70.

16. Cole FH, Cole FH Jr, Khandekar A, et al. Management of broncholithiasis: is thoracotomy necessary? Ann Thorac Surg 1986;42:255-7.

17. Trastek VF, Pairolero PC, Ceithaml EL, et al. Surgical management of broncholithiasis. J Thorac Cardiovasc Surg 1985;90:842-8.

18. Moersch HJ, Schmidt HW. Broncholithiasis. Ann Otol Rhinol Laryngol 1959;68:548-63.

19. Hammoud ZT, Rose AS, Hage CA, et al. Surgical management of pulmonary and mediastinal sequelae of histoplasmosis: a challenging spectrum. Ann Thorac Surg 2009;88:399-403.

20. Potaris K, Miller DL, Trastek VF, et al. Role of surgical resection in broncholithiasis. Ann Thorac Surg 2000;70:248-51; discussion 251-2.

21. Vix VA. Radiographic manifestations of broncholithiasis. Radiology 1978;128:295-9.

22. Igoe D, Lynch V, McNicholas WT. Broncholithiasis: bronchoscopic vs. surgical management. Respir Med 1990;84:163-5.

23. Reddy AJ, Govert JA, Sporn TA, et al. Broncholith removal using cryotherapy during flexible bronchoscopy: a case report. Chest 2007;132:1661-3.

24. Ferguson JS, Rippentrop JM, Fallon B, et al. Management of obstructing pulmonary broncholithiasis with threedimensional imaging and holmium laser lithotripsy. Chest 
2006;130:909-12.

25. Miks VM, Kvale PA, Riddle JM, et al. Broncholith removal using the YAG laser. Chest 1986;90:295-7.

26. Aust MR, Prakash UB, McDougall JC, et al. Bronchoscopic Broncholithotripsy. J Bronchology Interv Pulmonol 1994;1:37-41.

27. Prakash UB. The use of the pediatric fiberoptic bronchoscope in adults. Am Rev Respir Dis 1985;132:715-7.

28. Go T, Kobayashi H, Takata M, et al. Endoscopic management for broncholithiasis with bronchoesophageal fistula. Ann Thorac Surg 2007;84:2093-5.

29. Alraiyes AH, Desai R, Auron M, et al. Bronchoesophageal fistula secondary to broncholith. Qjm 2013;106:959-60.

30. McLean TR, Beall AC Jr, Jones JW. Massive hemoptysis due to broncholithiasis. Ann Thorac Surg 1991;52:1173-5.

31. Sakr L, Dutau H. Massive hemoptysis: an update on

Cite this article as: Krishnan S, Kniese CM, Mankins M, Heitkamp DE, Sheski FD, Kesler KA. Management of broncholithiasis. J Thorac Dis 2018;10(Suppl 28):S3419-S3427. doi: $10.21037 /$ jtd.2018.07.15 the role of bronchoscopy in diagnosis and management. Respiration 2010;80:38-58.

32. Uzun O, Erkan L, Haznedaroglu IC. Effective management of hemoptysis via endobronchial application of Ankaferd hemostat. Arch Bronconeumol 2014;50:407-9.

33. McCollun WB, Mattox KL, Guinn GA, et al. Immediate operative treatment for massive hemoptysis. Chest 1975;67:152-5.

34. Shao H, Wu J, Wu Q, et al. Bronchial artery embolization for hemoptysis: a retrospective observational study of 344 patients. Chin Med J (Engl) 2015;128:58-62.

35. Lin CS, Becker WH. Broncholith as a cause of fatal hemoptysis. JAMA 1978;239:2153.

36. Shaaban AM, Mann H, Morrell G, et al. A case of broncholithiasis and esophagobronchial fistula. J Thorac Imaging 2007;22:259-62. 